\title{
Comparative immune responses against Psoroptes ovis in two cattle breeds with different susceptibility to mange
}

\author{
Charlotte Sarre ${ }^{1}$, Ana González-Hernández ${ }^{1}$, Stefanie Van Coppernolle , Rika Grit ', Korneel Grauwet', \\ Frederik Van Meulder ${ }^{1}$, Koen Chiers' ${ }^{2}$, Wim Van den Broeck ${ }^{3}$, Peter Geldhof ${ }^{1}$ and Edwin Claerebout ${ }^{*}$
}

\begin{abstract}
The sheep scab mite, Psoroptes ovis, is a major problem in the beef cattle industry, especially in Belgian Blue (BB) cattle. This breed is naturally more predisposed to psoroptic mange but reasons for this high susceptibility remain unknown. Different immune responses could be a potential cause; thus in this study, the cutaneous immune response and in vitro cellular immune response after antigen re-stimulation were examined in naturally infested BB. Cytokine production in the skin and in circulating re-stimulated peripheral blood mononuclear cells (PBMC) demonstrated a mixed pro-inflammatory Th2/Th17 profile, with transcription of IL-4, IL-13, IL-6 and IL-17. Strong IL-17 up-regulation in the skin of BB was associated with an influx of eosinophils and other immune cells, potentially leading towards more severe symptoms. Virtually no changes in cutaneous IFN- $\gamma$ transcription were detected, while there was substantial IFN- $\gamma$ up-regulation in re-stimulated PBMC from infested and uninfested animals, potentially indicating a role of this pro-inflammatory cytokine in the innate immune response. In Holstein-Friesian (HF) cattle, generally more resistant to $P$. ovis infection, a largely similar immunologic response was observed. Differences between HF and BB were the lack of cutaneous IL-17 response in infested HF and low transcription levels of IFN- $\gamma$ and high IL-10 transcription in re-stimulated PBMC from both infested and uninfested animals. Further research is needed to identify potential cell sources and biological functions for these cytokines and to fully unravel the basis of this different breed susceptibility to P. ovis.
\end{abstract}

\section{Introduction}

Psoroptes ovis (P. ovis), the causative agent of psoroptic mange, causes severe allergic dermatitis and intense pruritus in sheep and cattle. The disease is highly contagious and causes impaired animal welfare and major economic losses due to performance loss and substantial treatment costs in livestock production all over the world [1-3]. Compared to sheep, $P$. ovis in cattle has a more limited geographical distribution, with a hotspot in Belgium where a farm prevalence of $75 \%$ has been observed on Belgian Blue (BB) beef farms [4]. This cattle breed appears to be highly susceptible to the infection, whilst other beef breeds and dairy cattle, such as Holstein-Friesians (HF),

\footnotetext{
*Correspondence: edwin.claerebout@ugent.be

${ }^{1}$ Department of Virology, Parasitology and Immunology, Faculty

of Veterinary Medicine, Ghent University, Merelbeke, Belgium

Full list of author information is available at the end of the article
}

seem to be more resistant, although the reason for this difference has not been clarified yet [5]. Host factors, such as genetic and immunologic variations, could be the cause of different breed susceptibility.

Previous research suggested that immune-depression was not responsible for higher susceptibility of $B B$, since BB animals developed $P$. ovis specific antibodies after infection, which correlated with the mite population density and the progression of the lesions. Moreover, in vitro culture of peripheral blood mononuclear cells (PBMC) showed an increased reactivity to mitogens [5-8]. In general, microscopic examination of the skin from infested ruminants reveals an increased dermal thickness and a superficial, perivascular dermatitis characterised by a fast influx of lymphocytes (including $\gamma \delta$ T-cells in sheep), macrophages, mast cells, neutrophils and eosinophils [9-12]. Previous work on sheep scab demonstrated an 
up-regulation of genes encoding for pro-inflammatory and pro-allergic mediators [interleukin (IL)-1, IL-8, IL-6] and molecules involved in extravasation of immune cells $[13,14]$. Several infectious diseases, including scabies, have been linked to CD4+ T-helper cell (Th) differentiation into specific Th1, Th2, Th17 or regulatory (Treg) lineages [15] and the pro-inflammatory response in the skin of $P$. ovis infested sheep evolves towards a Th2 immune response within $24 \mathrm{~h}$ after infection $[13,14,16]$. A similar pattern has been described in Sarcoptes scabiei infested mice and dogs with transcription of Th2 like cytokine profiles in lymph node cells and PBMC respectively [17, 18]. In addition, the epidermal differentiation complex (EDC) genes filaggrin, involucrin and loricrin are significantly down-regulated in infested sheep skin, indicating an impaired skin barrier function $[9,13]$ and markers of skin barrier disruption can also be found in circulating PBMC [16]. Furthermore, the systemic immune response parallels the cutaneous Th2 response as locally produced IL-4 and IL-13 stimulate PBMC to up-regulate IL-4R transcription and chemokine $(\mathrm{C}-\mathrm{C}$ motif) receptor 3 (CCR3), an eosinophil activator [16]. Remarkably, both $\mathrm{BB}$ and HF cattle showed an immediate hypersensitivity reaction $1 \mathrm{~h}$ after intradermal injection of Psoroptes cuniculi antigen, but only in BB animals a delayed hypersensitivity reaction after $72 \mathrm{~h}$ could be recorded $[5,7]$. Inherent differences in skin physiology and body composition could be responsible for this altered skin reaction in BB $[19,20]$.

As described for ticks [21, 22], susceptibility of cattle to mite infestations can also vary between individual animals. Increased susceptibility in sheep seems to correlate with higher numbers of eosinophils in the skin, larger lesions [11] and potential mutations in crucial EDC components $[9,13]$. Humans suffering from severe sarcoptic scabies, better known as crusted or Norwegian scabies, show a predominant immunoglobulin E (IgE)-driven Th2 response with high levels of IL- 5 and IL-13, in contrast to patients with ordinary scabies, who mainly express the Th1 cytokines IL-2 and IFN- $\gamma$ [23-25]. In mice and rabbits, a skewed Th2/Th1 response favouring the cell-mediated Th1 response is linked with lower antibody titres, also resulting in more resistant individuals [17, 26, 27]. Recent investigations demonstrate an important role for Th17 cytokines in humans suffering from chronic and/ or allergic inflammatory diseases, such as crusted scabies and psoriasis [28]. Moreover, in pigs with sarcoptic scabies, the development of severe symptoms is linked to higher levels of cutaneous IL-17, IL-23 but also Th2 cytokines IL-4 and IL-13 [23, 24, 28].

In conclusion, several potential reasons for differences in susceptibility to mange between breeds and between individual animals have been suggested in various species, with predominant roles for Th 2 and Th17 cytokines. Therefore, the main objective of this study was to examine the cutaneous and in vitro cellular immune responses to $P$. ovis infestation in the highly susceptible $\mathrm{BB}$ cattle breed. In addition, these responses were compared with those in more resistant HF cattle.

\section{Materials and methods}

Animals and tissue collection

Ethical approval to conduct this study was obtained from the Ethical Committee of the Faculty of Veterinary Medicine, Ghent University (ethical approval number EC 2013/130). In total 28 animals were sampled: 20 BB and $8 \mathrm{HF}$. All animals were females of approximately 1 year (BB) or 2-3 years (HF) old. The BB cattle were uninfested animals $(n=8)$ or naturally infested animals with severe clinical signs of mange $(n=12)$. The degree of infestation was quantified by calculating the percentage of infested body surface (clinical index, CI) for each animal based on the method of Guillot [29]. Heavily infested animals had a CI of $\geq 10 \%$ (range $12-45 \%$ ) and uninfested animals had a CI of $0 \%$. The HF were also either uninfested $(n=4)$ with $0 \% \mathrm{CI}$ or naturally infested with $P$. ovis $(n=4)$ with a CI of $\geq 1 \%$ (range $1-8 \%$ ). Skin scrapings of all infested animals demonstrated a pure $P$. ovis infection. The absence of mites in the uninfested groups was confirmed by indirect examination (centrifugation-flotation after 10\% potassium hydroxide digestion) of skin scrapings.

After confirmation of the presence or absence of P. ovis mites, two skin biopsies were taken per animal after shaving an area next to the tail base at the transition between healthy and infested skin, using a $4 \mathrm{~mm}$ diameter punch biopsy tool (Farla Medical). One biopsy was snap-frozen in liquid nitrogen and stored at $-70{ }^{\circ} \mathrm{C}$ to allow RNA extraction. The second skin sample was stored in $4 \%$ formaldehyde and paraffin-embedded for histology and immunohistochemistry. In addition, blood was drawn from the vena jugularis using heparin-coated tubes and PBMC were isolated using a Lymphoprep density gradient (Axis-Shield). The cells from the interphase were washed three times with Dulbecco's phosphate-buffered saline (DPBS; Invitrogen), counted and processed or cultured as described further.

\section{Psoroptes ovis antigen production}

Psoroptes ovis mites of a heavily infested BB animal were collected, washed with DPBS and stored at $-70{ }^{\circ} \mathrm{C}$. For crude protein extract production, the mites were washed again with ice cold DPBS and crushed in liquid nitrogen in a pestle and mortar. This extract was centrifuged at $16000 \mathrm{~g}$ for $30 \mathrm{~min}$ at $4{ }^{\circ} \mathrm{C}$ and sterilised over a $0.45 \mu \mathrm{m}$ filter (Millipore). Using the Bradford method (SigmaAldrich), the concentration of the supernatant was 
determined at $10 \mathrm{mg} / \mathrm{mL}$ [30] after which the extract was stored at $-70{ }^{\circ} \mathrm{C}$.

\section{Histology, immunohistochemistry and cell counts}

Tissue sections of the paraffin-embedded biopsies were stained with haematoxylin-eosin (HE) for the detection of eosinophils, toluidine blue staining for mast cells and two immunohistochemical stainings (CD3 staining for T-cells and CD20 staining for B-cells), based on Dreesen et al. [31]. In short, skin tissue sections of $4 \mu \mathrm{m}$ were mounted on APES-coated slides, blocked with $\mathrm{H}_{2} \mathrm{O}_{2}$ and stained with polyclonal rabbit anti-human CD3 (Dako, Belgium) or rabbit anti-human CD20 (Sigma-Aldrich, USA) antibodies. T- and B-cells were visualized by adding peroxidase labelled goat anti-rabbit antibodies (Dako, Belgium), diaminobenzidine tetrahydrochloride (DAB; Dako, Belgium) and by performing a counterstaining with haematoxylin. Eosinophils, mast cells, T-cells and B-cells were quantified by taking two random pictures per tissue slide at $400 \times$ magnification on a LEICA light microscope and counting the positive cells on two tissue slides per animal. Results were expressed as the number of cells per $10^{5} \mu \mathrm{m}^{2}$ tissue surface.

\section{Quantitative real-time polymerase chain reaction (qRT-PCR)}

The frozen skin samples that were crushed in liquid nitrogen, homogenized and phase separated in TRIzol (Invitrogen) were used for RNA purification according to Grit et al. [32]. In short, RNA was extracted from the aqueous phase using the RNeasy kit (Qiagen). On-column DNase digestion was included by using the RNase-free DNase set (Qiagen) and RNA concentrations were measured with a Nano-Drop 2000 spectrophotometer. In addition, PBMC were re-stimulated with either DPBS or $5 \mu \mathrm{g} / \mathrm{mL} P$. ovis antigen and cultured for 5 days in a 24-well flat-bottomed plate (BD Biosciences), after which the harvested cell pellets were washed 3 times with DPBS and stored at $-70{ }^{\circ} \mathrm{C}$ or directly used for on-column RNA purification as described above. cDNA was generated from 100 to $150 \mathrm{ng}$ total RNA using the iScript cDNA synthesis kit (Bio-rad). As the RNA yield from the PBMC of one uninfested HF was low, 60 ng RNA was used for the cDNA production of the PBMC from all uninfested HF $(n=4)$. The cDNA of all animals was diluted 1:10 in RNase free water and all qRTPCR analyses were carried out as described by Dreesen et al. [33] using the SYBR Green Master Mix (Applied Biosystems) on $2 \mu \mathrm{L}$ of single-stranded cDNA per reaction volume. All reactions were carried out in duplicate. Primer sequences and abbreviations for all genes that were tested are listed in Table 1. Using GeNorm software (geNorm 3.5), two breed specific internal control genes were selected from six candidate housekeeping genes: GADPH, HPRT1, RLPO, SDHA, RPS29 and HDAC10.
Analysis of the skin samples was performed with housekeeping genes SDHA and RPS29 for BB and HPRT1 and $S D H A$ for HF. Additional genes were tested to evaluate skin related pathology (Table 1). New primer sets for three EDC genes; filaggrin (FIL), involucrin (IVL) and loricrin $(L O R)$ were designed based on the following bovine reference gene sequences from the National Centre for Biotechnology Information (NCBI) database [34]: [FIL: XM_010826841, XM_010826842, XM_010826843], [IVL: XM_005203832, XM_010802998, XM_005203836] and [LOR: NM_001113757, XM_010826802, XM_010802876]. The sequences were aligned in SeqMan Pro (DNASTAR Lasergene) and primers were designed with Primer3web version 4.0.0 (free available online) (Table 1). Mean fold changes in gene transcription levels were obtained by comparing infested with control animals. For the analysis of the PBMC, housekeeping genes GAPDH and HPRT1 were used for normalization in the $\mathrm{BB}$ animals and RLPO and $S D H A$ for the HF. Relative quantities (Q values) were calculated using the delta $\mathrm{Ct}$ method to determine the fold differences in gene transcription levels of antigen re-stimulated cells of each animal compared to DPBS restimulated cells.

\section{Cell proliferation assays}

\section{${ }^{3} \mathrm{H}$-thymidine uptake assay}

For the ${ }^{3} \mathrm{H}$-thymidine uptake assay, $5 \times 10^{5}$ cells per well were cultured in a 96-well round-bottomed plate (Thermo Scientific) using $200 \mu \mathrm{L}$ of complete Roswell Park Memorial Institute (RPMI) cell culture medium, which consisted of RPMI-1640 (Invitrogen) supplemented with L-glutamine (Invitrogen), 10\% foetal calf serum (Moregate), gentamycin (Invitrogen) and $\beta$-mercaptoethanol (Sigma-Aldrich). The cells were either re-stimulated with a negative control (DPBS), $5 \mu \mathrm{g} /$ $\mathrm{mL}$ Concanavalin A (ConA, Sigma-Aldrich) as a positive control or $P$. ovis crude protein antigen at 5, 10, 25 or $50 \mu \mathrm{g} / \mathrm{mL}$. All conditions were performed in triplicate. The cells were pulsed with $1 \mu \mathrm{Ci}{ }^{3} \mathrm{H}$-thymidine (Perkin Elmer) after 4 days of culture. After $18 \mathrm{~h}$ of incubation, the cells were harvested and the incorporated radioactivity was measured using a $\beta$-scintillation counter (Perkin Elmer). Results are shown as stimulation indices (SI), which are the ratios of the counts per minute of $P$. ovis restimulated cells and the counts per minute of the negative control.

\section{PKH staining and flow cytometry}

To identify which cell populations from the whole PBMC fraction were proliferating after antigen re-stimulation, isolated PBMC were labelled with PKH using the PKH26 red fluorescent cell linker mini kit (Sigma-Aldrich) according to the manufacturer's protocol. A small 
Table 1 Primer sequences (cattle) and abbreviations of the genes used in the qRT-PCR assays, including GeneBank accession numbers.

\begin{tabular}{|c|c|c|}
\hline & Accession number & Primer sequence \\
\hline \multicolumn{3}{|l|}{ Housekeeping genes } \\
\hline $\begin{array}{l}\text { GAPDH } \\
\text { (glyceraldehyde-3-phosphate dehydrogenase) }\end{array}$ & NM_001034034.1 & $\begin{array}{l}\text { F: ACCCAGAAGACTGTGGATGG } \\
\text { R: CAACAGACACGTTGGGAGTG }\end{array}$ \\
\hline $\begin{array}{l}\text { HPRT1 } \\
\text { (hypoxanthine phosphoribosyltransferase 1) }\end{array}$ & NM_001034035.1 & $\begin{array}{l}\text { F: CACTGGGAAGACAATGCAGA } \\
\text { R: ACACTTCGAGGGGTCCTTTTT }\end{array}$ \\
\hline $\begin{array}{l}\text { RPS } 29 \\
\text { (ribosomal protein S29) }\end{array}$ & BC102702 & $\begin{array}{l}\text { F: GGAGCCATCCGAGAAAATTCG } \\
\text { R: CAACTTAATGAAGCCGATGTCCTT }\end{array}$ \\
\hline $\begin{array}{l}\text { RLPO } \\
\text { (ribosomal protein } P O)\end{array}$ & NM_001012682.1 & $\begin{array}{l}\text { F: CTTCATTGTGGGAGCAGACA } \\
\text { R: GGCAACAGTTTCTCCAGAGC }\end{array}$ \\
\hline $\begin{array}{l}\text { HDAC10 } \\
\text { (histone deacetylase 10) }\end{array}$ & NM_001075460.1 & $\begin{array}{l}\text { F: CCGATGACGGGAGAAATCTA } \\
\text { R: CTCAGGAACCCACCAGTTGT }\end{array}$ \\
\hline $\begin{array}{l}\text { SDHA } \\
\text { (succinate dehydrogenase complex subunit A) }\end{array}$ & NM_174178.2 & $\begin{array}{l}\text { F: ACATGCAGAAGTCGATGCAG } \\
\text { R: GGTCTCCACCAGGTCAGTGT }\end{array}$ \\
\hline \multicolumn{3}{|l|}{ qRT-PCR PBMC and skin } \\
\hline $\begin{array}{l}\text { IL-2 } \\
\text { (IL-interleukin) }\end{array}$ & NM_180997.1 & $\begin{array}{l}\text { F: TCCAAGCAAAAACCTGAACC } \\
\text { R: CAGCGTTTACTGTTGCATCATC }\end{array}$ \\
\hline $\mathbb{I L}-4$ & NM_173921.2 & $\begin{array}{l}\text { F: GCGGACTTGACAGGAATCTC } \\
\text { R:TCAGCGTACTTGTGCTCGTC }\end{array}$ \\
\hline $\operatorname{lL}-5$ & NM_173922.1 & $\begin{array}{l}\text { F:TGGTGGCAGAGACCTTGACA } \\
\text { R:TTCCCATCACCTATCAGCAGAGT }\end{array}$ \\
\hline $\mathbb{I L}-6$ & NM_173923.2 & $\begin{array}{l}\text { F:TCCTTGCTGCTTTCACACTC } \\
\text { R: CACCCCAGGCAGACTACTTC }\end{array}$ \\
\hline $\operatorname{IL}-10$ & NM_174088.1 & $\begin{array}{l}\text { F: TGTATCCACTTGCCAACCAG } \\
\text { R: CAGCAGAGACTGGGTCAACA }\end{array}$ \\
\hline $\operatorname{lL}-13$ & NM_174089.1 & $\begin{array}{l}\text { F: GGTGGCCTCACCTCCCCAAG } \\
\text { R: ATGACACTGCAGTTGGAGATGCTG }\end{array}$ \\
\hline $1 L-17$ & NM_001008412.1 & $\begin{array}{l}\text { F: GGACTCTCCACCGCAATGAG } \\
\text { R:TGGCCTCCCAGATCACAGA }\end{array}$ \\
\hline$I L-23 A$ & NM_001205688.1 & $\begin{array}{l}\text { F: CCCGTATCCAGTGTGAGGAT } \\
\text { R: AGTATGGAGGCGTGAAGCTG }\end{array}$ \\
\hline $\begin{array}{l}\text { FOXP3 } \\
\text { (forkhead box P3) }\end{array}$ & NM_001045933.1 & $\begin{array}{l}\text { F: GACAGCACCCTTTCGACTGT } \\
\text { R: CTCCAGAGATTGCACCACCT }\end{array}$ \\
\hline $\begin{array}{l}\text { IFN- } \gamma \\
\text { (interferon- } \gamma)\end{array}$ & NM_174086.1 & $\begin{array}{l}\text { F: TTCTTGAATGGCAGCTCTGA } \\
\text { R:TTCTCTTCGGCTTTCTGAGG }\end{array}$ \\
\hline $\begin{array}{l}\text { NCR1 } \\
\text { (natural cytotoxicity triggering receptor1) }\end{array}$ & NM_183365.1 & $\begin{array}{l}\text { F: CTGAGAGCGTGGGTGTATCA } \\
\text { R: CTGAGAGCGTGGGTGTATCA }\end{array}$ \\
\hline $\begin{array}{l}\text { TGF- } \beta 1 \\
\text { (transforming growth factor } \beta 1 \text { ) }\end{array}$ & NM_001166068.1 & $\begin{array}{l}\text { F: CTGCTGTGTTCGTCAGCTCT } \\
\text { R:TCCAGGCTCCAGATGTAAGG }\end{array}$ \\
\hline \multicolumn{3}{|l|}{ qRT-PCR skin } \\
\hline $\begin{array}{l}\text { AREG } \\
\text { (amphiregulin) }\end{array}$ & BC141281.1 & $\begin{array}{l}\text { F:TGGTCA } \\
\text { R: GTCGATCACGGAGGACAGTT }\end{array}$ \\
\hline $\begin{array}{l}\text { CCR3 } \\
\text { (chemokine receptor } 3 \text { ) }\end{array}$ & NM_001194960.1 & $\begin{array}{l}\text { F: TGTGTCAACCCCGTGATCTA } \\
\text { R: AGAGTTCCTGCTCCCCTGTT }\end{array}$ \\
\hline $\begin{array}{l}\text { FCERA1 } \\
\text { (FClgE receptora) }\end{array}$ & NM_001100310.1 & $\begin{array}{l}\text { F: CAGAGGCTGCCCTACATCTC } \\
\text { R: GTTTAGGCTGTGGGTCCGTA }\end{array}$ \\
\hline $\begin{array}{l}\text { FIL } \\
\text { (filaggrin) }\end{array}$ & * & $\begin{array}{l}\text { F: GCCCAGTTCTAGACGCTGAC } \\
\text { R:TCAAGCCAGTGACAGTGAGG }\end{array}$ \\
\hline $\begin{array}{l}\text { IVL } \\
\text { (involucrin) }\end{array}$ & * & $\begin{array}{l}\text { F: AAGGTCTTGGGCCAGCACTTG } \\
\text { R: GATGCTGGGTTGTAACTCCCCCCAC }\end{array}$ \\
\hline $\begin{array}{l}\text { LOR } \\
\text { (loricrin) }\end{array}$ & * & $\begin{array}{l}\text { F: CAGTGGATCCGTCTGCCTGGGA } \\
\text { R: CATGAGAGCGGTAAGCCCATCGAC }\end{array}$ \\
\hline
\end{tabular}

*Primers designed based on bovine reference gene sequences from NCBI database. 
fraction of the stained cells was used to determine the PKH starting intensity by flow cytometry analysis. The rest of the labelled cells was cultured at $5 \times 10^{5}$ cells per well in a 96-well round-bottomed plate (Thermo Scientific) in $200 \mu \mathrm{L}$ complete RPMI cell culture medium and re-stimulated with DPBS or $5 \mu \mathrm{g} / \mathrm{mL} P$. ovis. All conditions were performed in duplicate.

After 5 days of culture, the cells were harvested and two cell stainings were performed in DPBS supplemented with $1 \%$ bovine serum albumin (BSA, Sigma-Aldrich) and $0.1 \%$ Na-azide (Sigma-Aldrich) by using the following monoclonal primary antibodies: CD3 (mouse IgG1, clone MM1A, VMRD), TCR $\delta$ (mouse IgG2b, clone GB21A, VMRD), CD4 (mouse IgG2a, clone CC8) and CD8 (mouse IgM, clone BAQ111A, VMRD) in the first staining. CD3, CD21 (mouse IgM, clone BAQ15A, VMRD) and Alexa Fluor 488-labeled CD335 (mouse IgG2b, clone AKS6) in the second staining. The CD335 antibody was kindly provided by Prof. A. Storset (School of Veterinary Medicine, Norway). Bound mAb were detected using the following secondary antibodies: rat anti-mouse IgG1-V450 (BD Biosciences), rat anti-mouse IgG1-APC (BD Biosciences), rat anti-mouse IgG2b-FITC (Southern Biotech), goat anti-mouse IgG2a-APC (Invitrogen) and rat anti-mouse IgM-APCCy7 (Biolegend). The PKH intensity for each cell population was determined on a FACSAriaIII (BD Biosciences). Viable cells were gated based on forward and side scatter and lack of propidium iodide (Molecular Probes) uptake. Doublets were eliminated from the analysis by gating on forward scatter-height and forward scatter-area. T-cells were identified as $\mathrm{CD} 3+$ cells, T-helper cells as CD3+/CD4+ and cytotoxic T-cells as CD3+/CD8+. In the CD3- population, CD21+ cells were classified as B-cells, CD335+ cells as natural killer (NK)-cells and a third population of bovine CD3-/CD21-/CD335- cells was clearly defined but could not be identified so far.

Data were analysed using FlowJo software (Tree Star) and quantified using ModFit LT software (Verity Software House). Proliferation indices (PI) were calculated for each separate cell population and compared between DPBS and $P$. ovis antigen re-stimulated cells.

\section{Statistical analysis}

GraphPad Prism was used to perform all statistical analyses. For the comparison of the stimulation indices and $Q$ values (qRT-PCR on skin biopsies) between infested and uninfested animals, a nonparametric Mann-Whitney $U$ test was performed. A one-sided test was used for the stimulation indices and a two-sided test for the $Q$ values. Proliferation indices generated from the PKH staining and $\mathrm{Q}$ values of unstimulated vs. re-stimulated cells (qRT-PCR on PBMC) were compared using a nonparametric Wilcoxon signed-rank test: one-sided for the PKH data and two-sided for the $\mathrm{Q}$ values. $P$ values $\leq 0.05$ were considered statistically significant.

\section{Results}

In vivo cutaneous immune response

Results of the eosinophil, T- and B-cell and mast cell counts in the skin of infested and uninfested BB and HF animals are listed in Table 2. The number of eosinophils (46.7 per $10^{5} \mu \mathrm{m}^{2}$ ), T-cells $\left(83.8\right.$ per $10^{5} \mu \mathrm{m}^{2}$ ) and B-cells (30.6 per $10^{5} \mu \mathrm{m}^{2}$ ) was significantly higher in the infested BB than in the control animals $\left(6.5\right.$ per $10^{5} \mu \mathrm{m}^{2}, 33.8$ per $10^{5} \mu \mathrm{m}^{2}$ and 5.9 per $10^{5} \mu \mathrm{m}^{2}$ respectively), whereas the number of mast cells did not significantly differ. In HF animals, eosinophil, T-cell, B-cell and mast cell counts in the skin appeared to be higher in infested animals compared to the uninfested controls, although cell counts were not significantly different between the groups (Table 2).

To identify whether specific cytokines characteristic for a Th1, Th2 or Th17 immune response are produced during infection, qRT-PCR was performed on skin biopsies of uninfested and infested BB and HF animals (Figure 1). Only 11 infested $B B$ animals were included as from one animal an insufficient amount of RNA was obtained. A mixed Th2/Th17 cytokine profile was observed in the skin of infested BB with an up-regulation of IL-6 (6.2fold; $P=0.043)$ and IL-17 (6.3-fold; $P=0.006)$, as well as up-regulated transcription of IL-4 (3.2-fold; $P=0.012)$, IL-5 (1.6-fold; $P=0.149$ ), IL-13 (2.5-fold; $P=0.107$ ) and IL-10 (4.3-fold; $P=0.001)$. TGF- $\beta$ and NRC1 were also up-regulated in infested animals (1.4- and 2.5-fold and $P$ values of 0.006 and 0.003 respectively). Cutaneous transcription of IL-23 was down-regulated (0.7-fold; $P=0.019)$ and a low IFN- $\gamma(1.6$-fold; $P=0.159)$ response was observed.

Table 2 Histological cell counts in skin biopsies of control animals and Psoroptes ovis infested cattle.

\begin{tabular}{lllll}
\hline & $\begin{array}{l}\text { T-cells } \\
(\text { CD3+) }\end{array}$ & $\begin{array}{l}\text { B-cells } \\
(\text { CD20+) }\end{array}$ & Eosinophils & Mast cells \\
\hline A & & & & \\
$\begin{array}{c}\text { Control } \\
(n=8)\end{array}$ & $33.8 \pm 4$ & $5.9 \pm 1.1$ & $6.5 \pm 1.3$ & $12.4 \pm 1.2$ \\
$\begin{array}{c}\text { Infested } \\
(n=12)\end{array}$ & $83.8 \pm 7.8^{*}$ & $30.6 \pm 6.7^{*}$ & $46.7 \pm 4.9^{*}$ & $14.3 \pm 2.6$ \\
$\begin{array}{c}\text { B } \quad \\
\begin{array}{c}\text { Control } \\
(n=4)\end{array}\end{array}$ & $34.5 \pm 11.7$ & $5.8 \pm 0.8$ & $6.4 \pm 2.8$ & $12.5 \pm 1.2$ \\
$\begin{array}{c}\text { Infested } \\
(n=4)\end{array}$ & $46.6 \pm 5.4$ & $10.6 \pm 4$ & $35.1 \pm 10$ & $19 \pm 4.6$ \\
\hline
\end{tabular}

Panel A: Cell counts from Belgian Blue cattle. Panel B: Cell counts from HolsteinFriesian cattle. Data are presented as mean number of cells per $10^{5} \mu \mathrm{m}^{2} \pm \mathrm{SEM}$ (* $P<0.05)$. 


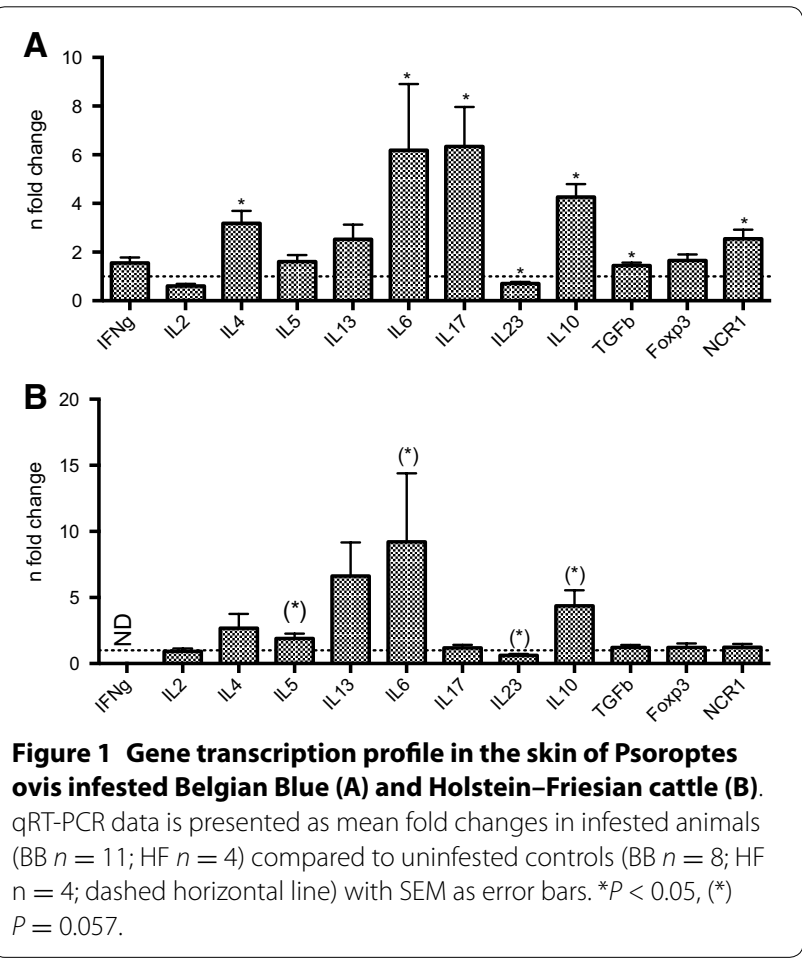

In general, these responses were comparable to those in HF cattle. The cytokine profile in the skin of HF demonstrated a predominant Th2-like response with upregulated transcription of IL-4 (2.7-fold; $P=0.686$ ), IL-5 (1.9-fold; $P=0.057$ ), IL-13 (6.6-fold; $P=0.124$ ) and IL-10 (4.4-fold; $P=0.057$ ). Virtually no change in IL-17 transcription (1.2-fold; $P=0.343$ ) was observed, while IL-6 was up-regulated (9.2-fold; $P=0.057)$. No significant changes in IL-23 transcription were observed in the skin (0.6-fold; $P=0.057$ ). IFN- $\gamma$ was up-regulated in three out of four infested animals, but could not be quantified as the transcription in the uninfested control animals was too low to detect.

\section{In vitro immune response after PBMC re-stimulation}

Proliferation of re-stimulated PBMC was assessed using a ${ }^{3} \mathrm{H}$-thymidine uptake assay, in which cells from uninfested and infested BB and HF animals were re-stimulated with either DPBS as negative control, ConA as positive control or several concentrations of $P$. ovis antigen $(5,10,25$ or $50 \mu \mathrm{g} / \mathrm{mL})$. Results demonstrated a significant and largely concentration-dependent PBMC proliferation in infested $\mathrm{BB}$ and $\mathrm{HF}$ compared to the uninfested animals (Figures $2 \mathrm{~A}$ and $\mathrm{B}$ ).

Using PKH staining on cells of infested BB and HF re-stimulated with $5 \mu \mathrm{g} / \mathrm{mL}$ antigen or DPBS, a significant antigen specific proliferation in all investigated cell populations $(\alpha \beta$ T-cells, $\gamma \delta$ T-cells, B-cells, NK-cells and CD3-/CD21-/CD335- cells) was observed, with the highest reaction seen in NK- and CD3-/CD21-/ CD335- cells (Figures $2 \mathrm{C}$ and D).

It was subsequently investigated whether circulating re-stimulated PBMC of infested BB and HF animals after in vitro re-stimulation with $P$. ovis antigen produced similar cytokines as in the skin (Figure 3). As the RNA yield of one infested $\mathrm{BB}$ animal was insufficient to perform qRT-PCR, data of 11 instead of $12 \mathrm{BB}$ animals is shown in Figure 3A. In parallel to the cutaneous immune response, re-stimulation of PBMC in infested $\mathrm{BB}$ induced a predominant Th2- and Th17-like response with up-regulated transcription of IL-4 (11-fold; $P=0.019$ ), IL-13 (58.6fold; $P=0.001$ ) and IL17 (45.5-fold; $P=0.003$ ). In addition, an up-regulation of Foxp3 (1.9-fold; $P=0.032)$ and NCR1 (3.5-fold; $P=0.003$ ) transcription was observed, as well as of IFN- $\gamma$ (36.8-fold; $P=0.003)$, IL-5 (3.5-fold; $P=0.413)$, IL-10 (2.5-fold; $P=0.102)$ and IL-6 (12.5fold; $P=0.831$ ). TGF- $\beta$, IL-2 and IL-23 transcription were down-regulated (all 0.5 -fold with $P$-values of 0.001 , 0.005 and 0.001 respectively).

The cytokine profile of circulating re-stimulated PBMC in infested HF animals (Figure 3B) revealed a mixed Th2/ Th17-like response with 2.6-, 11.5- and 19.4-fold changes for IL-5, IL-13 and IL-6 respectively. IL-17 and IL-10 were consistently up-regulated in all samples (average fold changes of 69.1 and 8.5 respectively), systemic IFN- $\gamma$ was 2.4-fold up-regulated and IL-23, TGF- $\beta$ and IL-2 were slightly down-regulated, with $0.9-, 0.8$ - and 0.5 -fold changes respectively. However, the statistical significance for these data could not be interpreted due to the combination of a low number of animals $(n=4)$ and the use of a two-sided paired statistical test.

In order to evaluate whether these observations were mainly due to a cellular memory response or whether innate reactions were also responsible, the same procedure was followed for the uninfested BB $(n=8)$ and HF $(n=4)$ animals with the results listed in Figure 4. A 17.3-fold $(P=0.039), 7.2$-fold $(P=0.031)$ and 376.8 -fold $(P=0.039)$ up-regulation of respectively IL-13, IL-17 and IFN- $\gamma$ was observed in BB animals (Figure 4A). Finally, qRT-PCR results from the re-stimulated $\mathrm{PBMC}$ of uninfested $\mathrm{HF}$ animals are listed in Figure 4B and show an up-regulation of IL-13 (14.2-fold) and IL-10 (25.5-fold). In contrast with the PBMC from uninfested BB cattle, virtually no IL-17 response and a moderate IFN- $\gamma$ up-regulation (1.9- and 5.3-fold respectively) were observed in uninfested HF. For the results in HF, the statistical significance could not be interpreted for the same reasons as mentioned above.

\section{Discussion}

In this study, the cutaneous immune response and in vitro cellular immune reaction in $\mathrm{BB}$ and $\mathrm{HF}$ cattle 

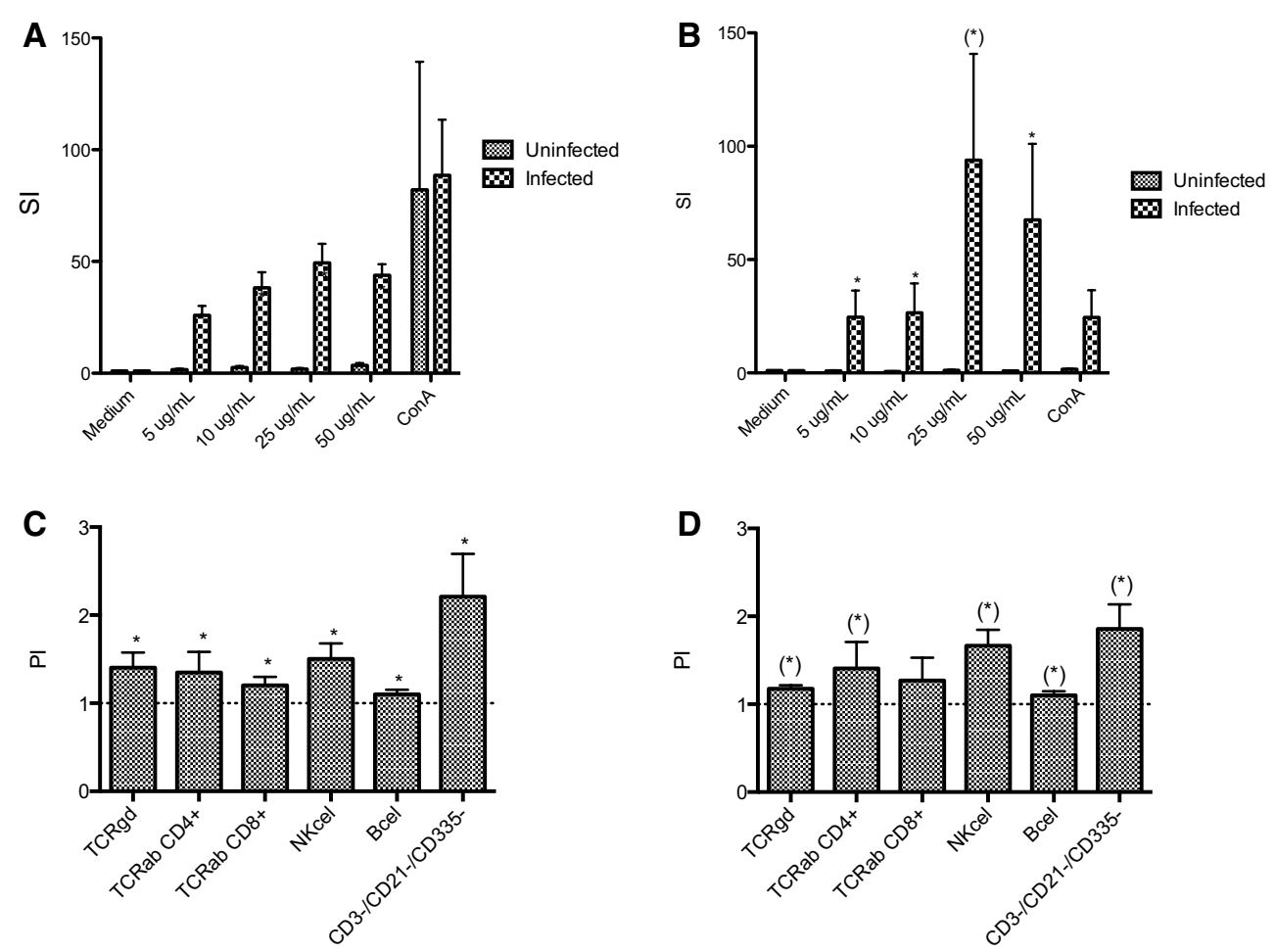

Figure $2{ }^{3} \mathrm{H}$-thymidine uptake assay and PKH staining of circulating PBMC from (un)infested Belgian Blue and Holstein-Friesian cattle. A Mean stimulation index (SI \pm SEM) of PBMC from uninfested $(n=8)$ and infested $(n=12)$ BB cattle re-stimulated with medium, 4 different concentrations of $P$. ovis and ConA. B Mean stimulation index (SI \pm SEM) of PBMC from uninfested $(n=4)$ and infested $(n=4) \mathrm{HF}$ cattle re-stimulated with medium, four different concentrations of P. ovis and ConA. C Mean proliferation index (PI \pm SEM) of PKH labelled PBMC re-stimulated with $5 \mu \mathrm{g} / \mathrm{mL}$ P. ovis antigen compared to unstimulated PBMC (dashed horizontal line) of infested BB $(n=12)$. D Mean proliferation index (PI \pm SEM) of PKH labelled PBMC re-stimulated with $5 \mu \mathrm{g} / \mathrm{mL}$ P. ovis antigen compared to unstimulated PBMC (dashed horizontal line) of infested HF ( $n=4$ ). ${ }^{*} P<0.05,\left({ }^{*}\right) P=0.057$.

during natural $P$. ovis infestation were analysed in order to identify a potential cause of the high susceptibility of the $\mathrm{BB}$ breed to this parasitic infestation. A significant influx of immune cells in the skin of infested BB was observed, coinciding with a mixed Th2/Th17 cytokine profile. A largely similar cytokine pattern could be elicited when circulating PBMC from infested BB were restimulated with $P$. ovis antigen in vitro. Moreover, a significant and largely antigen concentration-dependent PBMC proliferation was observed in infested animals compared to uninfested controls, with proliferation of all investigated cell subpopulations $(\alpha \beta$ T-cells, $\gamma \delta$ T-cells, B-cells, NK-cells and CD3-/CD21-/CD335- cells). This demonstrates the presence of antigen specific memory T-cells, and it confirms previous assumptions that an impaired cellular immune response in $\mathrm{BB}$ is not the cause of the high susceptibility of this breed [5]. HF animals are known to display less severe symptoms during $P$. ovis infection in comparison to $\mathrm{BB}$, which is reflected in the lower $\mathrm{CI}$ of the animals in this study and the less pronounced influx of immune cells in infested skin.
Although the cytokine pattern observed in the skin was similar to that in BB, no cutaneous IL-17 production was observed in infested HF. Furthermore, circulating PBMC from infested HF also produced a less pronounced Th2like response. It should however be stressed that a different mite exposure in vivo could be responsible for these observations. Furthermore, the infestation stage of the animals was unclear and there was a small age difference between the animals, which could also partly explain the differences between both breeds.

Th2 and Th17 cytokines have been described as being important in parasitic skin diseases. Production of Th2 cytokines is often observed in ectoparasite infections in cattle as it is in dogs, rabbits and mice with scabies [17, $18,26,27]$. The cutaneous mixed Th2/Th17 profile that is observed in BB could potentially be associated with more severe symptoms, as described in pigs with aggravating symptoms of Sarcoptes scabiei and in allergic diseases in humans [23, 28, 35]. Although this specific immune response could merely be a reaction to the presence of severe symptoms linked with high numbers of mites, the 

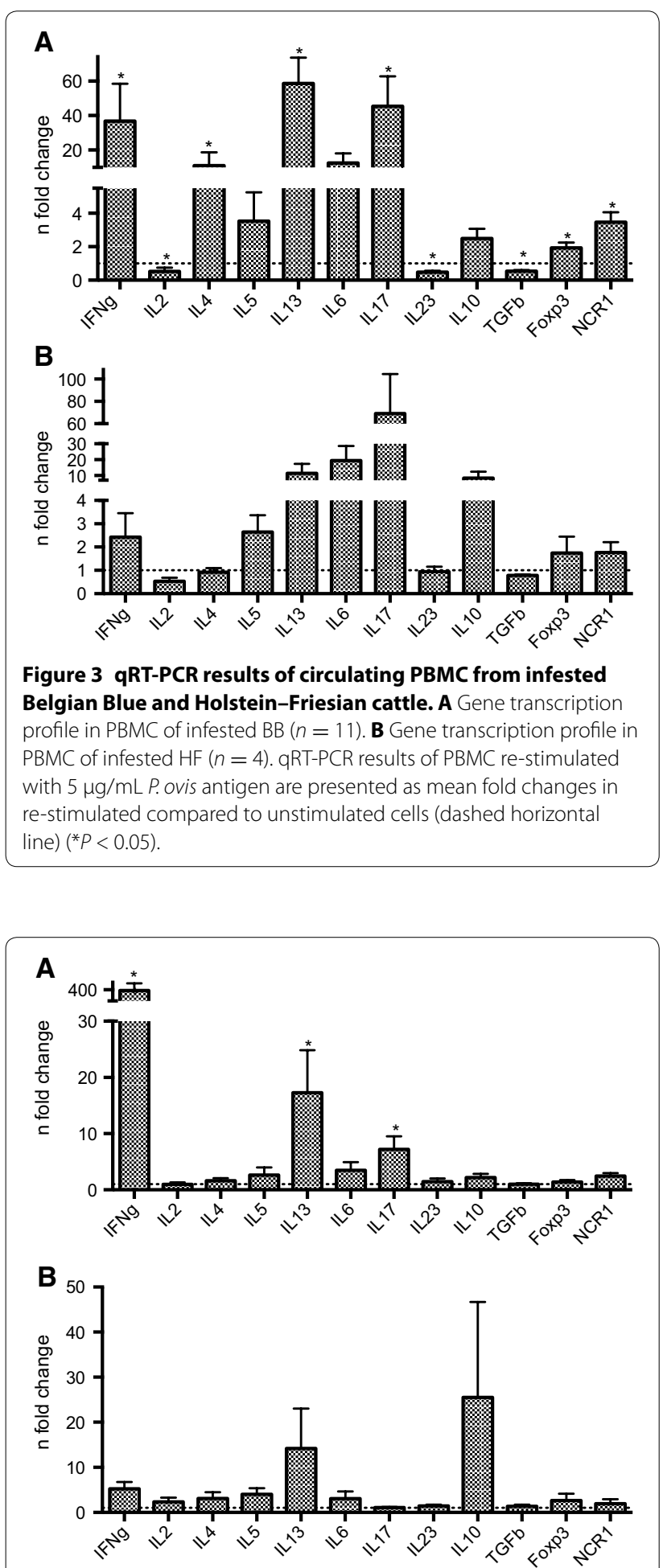

Figure 4 qRT-PCR results of circulating PBMC from uninfested Belgian Blue and Holstein-Friesian cattle. A Gene transcription profile in PBMC of uninfested BB $(n=8)$. B Gene transcription profile in PBMC of uninfested HF $(n=4)$. qRT-PCR results of PBMC re-stimulated with $5 \mu \mathrm{g} / \mathrm{mL}$ P. ovis antigen are presented as mean fold changes in re-stimulated compared to unstimulated cells (dashed horizontal line) $\left({ }^{*} P<0.05\right)$ reversed hypothesis is also plausible. Indeed, Th2 cytokines produced in the skin will not only stimulate local immune cells to attack the mites, but will also cause collateral damage to the surrounding tissue, leading to the clinical symptoms. Despite the IL-23 down-regulation, the additional pro-inflammatory Th17-like response in BB could intensify these effects leading to a more severe clinical phenotype. As mite counts were not performed in this study, it remains unsure whether this Th2/Th17-like response in infested $\mathrm{BB}$ animals is either not protective or is protective but "uncontrollable". Little to no signs of a Treg reaction that could dampen this pro-inflammatory response, were noticed in both breeds, as only IL-10, which is also a Th2 cytokine, was up-regulated, without transcription of TGF$\beta$. Furthermore, only a diminutive up-regulation of Foxp3, a transcription factor that is generally expressed by Treg T-cells [36, 37] was noticed. Remarkably, little to no IFN- $\gamma$ was transcribed in the skin of infested BB, while substantial up-regulation of this pro-inflammatory cytokine was observed in re-stimulated PBMC from infested and uninfested BB. The latter indicates that IFN- $\gamma$ could mainly be released by innate immune cells, such as macrophages, NKT- or NK-cells [36]. Low levels of this cytokine in the skin could be caused by the fact that the adaptive immune response already took over at this point of infection. Production of IFN- $\gamma$, a pro-inflammatory cytokine that pushes naïve T-cells towards Th1-cells [36], has been described in murine spleen and lymph node cells in vitro after challenge infection with Sarcoptes scabiei [17]. In contrast with the uninfested $\mathrm{BB}$, low IFN- $\gamma$ and high IL-10 levels were observed in the re-stimulated PBMC from uninfested HF animals. It remains unclear why IFN- $\gamma$ and IL-10 transcription in HF does not resemble the pattern observed in $\mathrm{BB}$ and it should be further investigated whether this could be part of the cause of different breed susceptibility.

The mixed cytokine profile seen in BB may have an effect on several immune cells downstream. Th2 cytokines are known to promote the immune response to parasites: IL-4 and IL-13 play a role in the induction of allergy as they stimulate B-cell growth and IgE production, whilst IL-5 typically induces eosinophil differentiation and growth [36]. The pro-inflammatory effect of IL-17 causes recruitment of neutrophils and further promotes the attraction of eosinophils in the skin [35, 38]. Indeed, besides the recruitment of $\mathrm{T}$ - and $\mathrm{B}$-cells, cell counts demonstrated a distinct influx of eosinophils in the skin of affected BB and a greater eosinophil skin infiltration has also been documented in sheep breeds susceptible to $P$. ovis and cattle breeds susceptible to tick infestations $[11,22]$. The presence of high levels of IL-17 in the skin has also been linked to delayed-type hypersensitivity in humans [38], which could explain the distinctive intradermal skin test response observed by Losson et al. $[5,7]$. 
In this study, no suppression of the transcription of EDC genes could be observed (results not shown), unlike data available in sheep. As a down-regulation of these genes in sheep skin is seen within $24 \mathrm{~h}$ after infection, it is possible that this was missed in this study $[9,13]$.

In summary, BB cattle display a mixed Th2/Th17 immune pathway during natural infection with $P$. ovis. We hypothesize that, in line with results from scabies affected humans and pigs, this might explain part of their susceptibility since no cutaneous Th17 profile could be detected in the more resistant HF breed. Furthermore, in contrast to the results from the HF, high transcription levels of IFN- $\gamma$ and low IL-10 transcription in the uninfested and infested $\mathrm{BB}$ could indicate a potential role for these cytokines in the innate immune reaction against the mite. These differences in IFN- $\gamma$ and IL-10 transcription could therefore also be partly responsible for the observed difference in breed susceptibility to mange. Further research is needed to identify potential cell sources and biological functions for these up-regulated cytokines and to fully unravel the basis of this different breed susceptibility to $P$. ovis.

\section{Authors' contributions \\ CS participated in the design of the study, performed the blood and biopsy sampling, carried out all in vitro tests, performed the qRT-PCR and the cell counts and drafted the manuscript. SVC and RG optimized the in vitro tests. AG-H and KG assisted during the in vitro work and flow cytometry respec- tively. FVM optimized the RNA purification. KC performed the immunohis- tochemical and WVDB the histological stainings. PG and EC participated in the study design, coordinated all activities of this project and revised the manuscript. All authors read and approved the final manuscript.}

\section{Author details \\ ${ }^{1}$ Department of Virology, Parasitology and Immunology, Faculty of Veterinary Medicine, Ghent University, Merelbeke, Belgium. ${ }^{2}$ Department of Pathology, Bacteriology and Poultry Diseases, Faculty of Veterinary Medicine, Ghent University, Merelbeke, Belgium. ${ }^{3}$ Department of Morphology, Faculty of Veteri- nary Medicine, Ghent University, Merelbeke, Belgium. \\ Acknowledgements \\ The authors would like to thank all the farmers involved in this study. Also Nathalie De Wilde and Stijn Casaert for their excellent technical support. This work was partly funded by the Belgian Federal Government (PSOROVIS project). FVM and RG were supported by the Agency for Innovation through Science and Technology-Flanders (Belgium) (IWT-Vlaanderen) and AG-H and KG by grants from the Special Research Fund of Ghent University (BOF Research Project). SVC was funded by the EU 7th Framework Program (PARA- VAC Project).}

\section{Competing interests}

The authors declare that they have no competing interests.

Received: 17 July 2015 Accepted: 19 October 2015

Published online: 19 November 2015

\section{References}

1. Kirkwood AC (1986) History, biology and control of sheep scab. Parasitol Today 2:302-307

2. Lonneux J-F, Nguyen TQ, Detry J, Farnir F, Losson BJ (1998) The relationship between parasite counts, lesions, antibody titres and daily weight gains in Psoroptes ovis infested cattle. Vet Parasitol 76:137-148
3. Pouplard L, Losson B, Detry M, Hollanders W (1990) Les gales bovines. Ann Med Vet 134:531-539 (in French)

4. Sarre C, De Bleecker K, Deprez P, Levecke B, Charlier J, Vercruysse J, Claerebout E (2012) Risk factors for Psoroptes ovis mange on Belgian Blue farms in Northern Belgium. Vet Parasitol 190:216-221

5. Losson BJ, Lonneux J-F, Lekimme M (1999) The pathology of Psoroptes ovis infestation in cattle with a special emphasis on breed difference. Vet Parasitol 83:219-229

6. Lonneux J-F, Nguyen TQ, Hollanders W, Denis M, Thiry E, Pastoret PP, Losson B (1998) Humoral and cell-mediated immune responses of beef and dairy cattle experimentally infested with Psoroptes ovis. Am J Vet Res 59:583-587

7. Losson B, Detry-Pouplard M, Pouplard L (1988) Haematological and immunological response of unstrained cattle to Psoroptes ovis, the sheep scab mite. Res Vet Sci 44:197-201

8. Pruett JH, Guillot FS, Fisher WF (1986) Humoral and cellular immunoresponsiveness of stanchioned cattle infested with Psoroptes ovis. Vet Parasitol 22:121-133

9. Stoeckli MR, McNeilly TN, Frew D, Marr EJ, Nisbet AJ, van den Broek AHM, Burgess STG (2013) The effect of Psoroptes ovis infestation on ovine epidermal barrier function. Vet Res 44:11

10. Stromberg PC, Guillot FS (1989) Pathogenesis of psoroptic scabies in Hereford heifer calves. Am J Vet Res 50:594-601

11. van den Broek AH, Huntley JF (2003) Sheep scab: the disease, pathogenesis and control. J Comp Pathol 128:79-97

12. van den Broek AHM, Huntley JF, Mackellar A, Machell J, Taylor MA, Miller HRP (2005) Characterisation of lesional infiltrates of dendritic cells and T cell subtypes during primary infestation of sheep with Psoroptes ovis, the sheep scab mite. Vet Immunol Immunopathol 105:141-150

13. Burgess STG, Frew D, Nunn F, Watkins CA, McNeilly TN, Nisbet AJ, Huntley JF (2010) Transcriptomic analysis of the temporal host response to skin infestation with the ectoparasitic mite Psoroptes ovis. BMC Genom 11:624

14. Burgess STG, McNeilly TN, Watkins CA, Nisbet AJ, Huntley JF (2011) Host transcription factors in the immediate pro-inflammatory response to the parasitic mite Psoroptes ovis. PloS One 6:e24402

15. Babu S, Bhat SQ, Kumar NP, Kumaraswami V, Nutman T (2010) Regulatory T cells modulate Th17 response in patients with positive tuberculin skin test results. J Infect Dis 201:20-31

16. Burgess STG, Greer A, Frew D, Wells B, Marr EJ, Nisbet AJ, Huntley JF (2012) Transcriptomic analysis of circulating leukocytes reveals novel aspects of the host systemic inflammatory response to sheep scab mites. PLoS One 7:e42778

17. Lalli PN, Morgan MS, Arlian LG (2004) Skewed Th1/Th2 immune response to Sarcoptes scabiei. J Parasitol 90:711-714

18. Singh SK, Dimri U, Sharma B, Saxena M, Kumari P (2014) Assessment of the cytokine profile in peripheral blood mononuclear cells of naturally Sarcoptes scabiei var. canis infested dogs. Vet Parasitol 206:253-257

19. Sallovitz J, Lifschitz A, Imperiale F, Pis A, Virkel G, Lanusse C (2002) Breed differences on the plasma availability of moxidectin administered pouron to calves. Vet J 164:47-53

20. Vercruysse J, Deprez P, Everaert D, Bassissi F, Alvinerie M (2008) Breed differences in the pharmacokinetics of ivermectin administered subcutaneously to Holstein and Belgian Blue cattle. Vet Parasitol 152:136-140

21. Piper EK, Jonsson NN, Gondro C, Lew-Tabor AE, Moolhuijzen P, Vance ME, Jackson LA (2009) Immunological profiles of Bos taurus and Bos indicus cattle infested with the cattle tick, Rhipicephalus (Boophilus) microplus. Clin Vaccine Immunol 16:1074-1086

22. Piper EK, Jackson LA, Bielefeldt-Ohmann H, Gondro C, Lew-Tabor AE, Jonsson NN (2010) Tick-susceptible Bos taurus cattle display an increased cellular response at the site of larval Rhipicephalus (Boophilus) microplus attachment, compared with tick-resistant Bos indicus cattle. Int J Parasitol 40:431-441

23. Mounsey KE, Murray HC, Bielefeldt-Ohmann H, Pasay C, Holt DC, Currie BJ, Walton SF, McCarthy JS (2015) Prospective study in a porcine model of Sarcoptes scabiei indicates the association of Th2 and Th17 pathways with the clinical severity of scabies. PLoS Negl Trop Dis 9:e0003498

24. Walton SF, Oprescu FI (2013) Immunolgy of scabies and translational outcomes: identifying the missing links. Curr Opin Infect Dis 26:116-122

25. Walton SF (2010) The immunology of susceptibility and resistance to scabies. Parasite Immunol 32:532-540 
26. Arlian LG, Rapp CM, Morgan MS (1995) Resistance and immune response in scabies-infested hosts immunized with Dermatophagoides mites. Am J Trop Med Hyg 52:539-545

27. Casais R, Dalton KP, Millán J, Balseiro A, Oleaga Á, Solano P, Goyache F, Prieto JM, Parra F (2014) Primary and secondary experimental infestation of rabbits (Oryctolagus cuniculus) with Sarcoptes scabiei from a wild rabbit: factors determining resistance to reinfestation. Vet Parasitol 203:173-183

28. Liu X, Walton SF, Murray HC, King M, Kelly A, Holt DC, Currie BJ, McCarthy JS, Mounsey KE (2014) Crusted scabies is associated with increased IL-17 secretion by skin T cells. Parasite Immunol 36:594-604

29. Guillot FS (1981) Population increase of Psoroptes ovis (Acari: psoroptidae) on stanchioned cattle during summer. J Med Entomol 18:44-47

30. Bradford MM (1976) A rapid and sensitive method for the quantification of microgram quantities of protein utilizing the principle of protein-dye binding. Anal Biochem 72:248-254

31. Dreesen L, Rinaldi M, Chiers K, Li R, Geurden T, Van den Broeck W, Goddeeris B, Vercruysse J, Claerebout E, Geldhof P (2012) Microarray analysis of the intestinal host response in Giardia duodenalis assemblage E infected calves. PLoS One 7:e40985

32. Grit GH, Devriendt B, Van Coppernolle S, Geurden T, Hope J, Vercruysse J, Cox E, Geldhof P, Claerebout E (2014) Giardia duodenalis stimulates partial maturation of bovine dendritic cells associated with altered cytokine secretion and induction of T-cell proliferation. Parasite Immunol 36:157-169

33. Dreesen L, De Bosscher K, Grit G, Staels B, Lubberts E, Bauge E, Geldhof $P$ (2014) Giardia muris infection in mice is associated with a protective interleukin 17A response and induction of peroxisome proliferatoractivated receptor alpha. Infect Immun 82:3333-3340

34. NCBI database. https://www.ncbi.nlm.nih.gov/. Accessed 16 Mar 2015

35. Li CW, Lu HG, Chen DH, Lin ZB, Wang DY, Li TY (2014) In vivo and in vitro studies of Th17 response to specific immunotherapy in house dust miteinduced allergic rhinitis patients. PLoS One 9:e91950

36. Murphy K (2012) T-cell mediated immunity. In: Janeway's immunobiology, 8th edn. Garland Science Taylor \& Francis Group, London

37. McNeilly TN, McIntyre J, Frew D, Griffiths DJ, Wattegedera R, van den Broek A, Huntley JF (2010) Infestation of sheep with Psoroptes ovis, the sheep scab mite, results in recruitment of Foxp3 ${ }^{+} \mathrm{T}$ cells into the dermis. Parasite Immunol 32:361-369

38. Iwakura $Y$, Ishigame $H$ (2006) The IL-23/IL-17 axis in inflammation. J Clin Invest 116:1218-1222

\section{Submit your next manuscript to BioMed Central and take full advantage of:}

- Convenient online submission

- Thorough peer review

- No space constraints or color figure charges

- Immediate publication on acceptance

- Inclusion in PubMed, CAS, Scopus and Google Scholar

- Research which is freely available for redistribution

Submit your manuscript at

www.biomedcentral.com/submit

C Biomed Central 